\title{
The Intergenerational Transmission of the Value of Children in Contemporary Chinese Families: Taiwan and Mainland China Compared
}

\author{
Chin-Chun Yi, Yu-Hua Chen
}

\begin{abstract}
While fertility has been drastically declining in East Asia, mechanisms accounting for the current trend vary. One noticeable mechanism documented is that the changing value of children affects couples' fertility decisions which in turn affect their subsequent fertility behaviour. This study will examine the intergenerational transmission of the value of children (VOC) among grandmothers, mothers and teenagers in two Chinese societies: Taiwan and Mainland China. We assume that cultural homogeneity interacts with political and social heterogeneity and may result in different values regarding having or not having children. Data are taken from two corresponding VOC surveys from Taiwan (2005-2007) and from Mainland China (2002-2003). We first compare the value of children for Taiwan and Mainland China with special attention to cultural aspects. Two identified factor solutions are generated for both positive (traditional and emotional) and negative (emotional/psychological and familial/social) VOC. Analyses show that intergenerational transmission of the VOC among three generations is more likely to occur for a positive VOC in the Chinese Mainland sample. We suspect that actual fertility experience results in greater resemblance on the VOC between grandmothers and mothers in both research settings. Among selected structural mechanisms, only rural-urban background has an effect on patterns of intergenerational transmission. The paper ends with a discussion on the importance of culture in explaining the intergenerational transmission of the VOC in Chinese societies.
\end{abstract}

Keywords: Value of children · Intergenerational transmission - Taiwanese fertility values $\cdot$ Chinese fertility values 


\section{$1 \quad$ Research background}

In the midst of a global fertility decline, a particularly sharp drop has occurred in East Asia. In 2011, the total fertility rate in the region ranged from a low of 0.9 in Taiwan to 1.5 in Mainland China, with Japan (1.4), South Korea (1.2) and Hong Kong (1.1) in between. The interaction between rapid social change and its concomitant value changes has been repeatedly documented to result in significant changes in family and demography related behaviours (Lu 2011; McDonald 2000; Tu/Liao 2005; Yeh et al, 2013). Hence, this study discusses that embedded in a cultural context of patriarchal practice in the region, the low fertility rate certainly reflects rapid changes in family values in general and in values toward children in particular.

Over the last decades, numerous efforts have been made in locating important mechanisms accounting for couples not wanting to have children in this relatively traditional region. In general, three salient factors have been proposed:

(1) Increased human capital. While both men and women tend to stay longer in a school context than previous generations, women's' educational attainment exhibits clearer improvement. Hence, marriage is postponed and subsequently, childbearing is delayed or even denied biologically (Cai 2010; Jones et al. 2009).

(2) The rise of dual-earner families. Labour force participation is often accompanied by a higher educational attainment, especially for women. The advantage of a dual-earner family includes better family finances as well as selffulfilment (Yu 2009). However, the demand of child-rearing becomes costly for couples who are both in the labour market. This problem is aggravated by the sharp decline in three-generational households in recent decades which results in a lack of help with childcare by grandparents (Yi et al. 2006).

(3) Emergence of egalitarian gender ideology. The expectation of husbands actively sharing and engaging in housework has brought about a gender revolution at home ( $L u$ 2011). This ideological shift, taking place in the context of a traditional patriarchal system, contributes to the hesitance to marry women with greater resources such as a higher education or a high income (Chen/Yi 2005).

While the above explanation of low fertility tends to be similar to that in reports from the West, the situation is much more acute in East Asia due to its strong familial belief as well as its short history of modernisation. Significant structural explanations are offered for the continuing low fertility but there may be salient individual mechanisms just as important in explaining the low fertility phenomenon. One noted mechanism documented is the value of children (VOC) of couples which may directly affect their fertility decision (Nauck 2007). This paper will examine the VOC expressed in the low fertility societies in East Asia. In order to generate meaningful comparisons two Chinese societies, Taiwan and Mainland China, are selected due to their cultural and historical homogeneity as well as socio-political heterogeneity. Specifically, .Confucian doctrine and practices are shared cultural traditions among different Chinese societies in which filial piety and the proper order by age were considered the highest values (Blitsten 1963; Lang 1968; Yang 1973). Recent historical developments, however, diverge between Taiwan and Mainland China. Taiwan 
with its rapid modernisation process has been under strong Western cultural influences while Mainland China with long years of exclusion has been coping with the one-child policy within the family as well as in the societal context. It is thus important to examine the potential cultural influences on individual values from general versus specific historical experiences.

It should be noted that there is strong empirical support for the Confucian value placed upon family as the baseline of social structure in different countries in East Asia (Hsu 1948; Sung 1995; Koyano 1996; Deutsch 2006; Whyte 1995) and it is also confirmed to manifest its utility across generations (Yeh 1997). Against this research background, we will explore the potential continuity of the specified family value in Mainland China and Taiwan. Our contention is that even in an era of rapid social change, fundamental cultural beliefs will be somewhat stable and thus, similar patterns of an intergenerational transmission of the VOC may be observed in different Chinese societies. On the other hand, experiences from heterogeneous social systems may lead to different values on children and family. It is expected that findings will allow us to ascertain the significance of the individual VOC shaped by the common cultural as well as changing social context

\section{Research issues}

Unlike the first VOC study which was launched in the 1970s when the threat of a population explosion caught serious attention, the second VOC study in the 2000s aimed to explore the emergence of low fertility in many parts of the world. To deal with the diversity of fertility trends in different regions, the value of children was proposed to be a powerful concept contributing to the analysis fertility decisions (Trommsdorff/Nauck 2005). Nauck and Klaus (2007), after analysing empirical evidence from 11 countries, conclude that a significant difference exists between lineage-based kinship systems and state-based insurance systems with regard to both actual fertility and preferred value dimensions. However, even within the similar context of a lineage-based kinship system, fertility values and behaviours vary. Previous attempts to solve this puzzle have produced seemingly contradictory results. It is obvious that the rapid socioeconomic transformation in East Asia has significantly reduced fertility but a relatively strong preference for sons which positively increases the intention to bear children still prevails in this region (Das Gupta 2009; Westley/Choe 2007; Song/Burgard 2008; Filmer et al. 2008). It is therefore necessary to compare two societies with similar cultural heritage and different social systems so as to delineate the underlying mechanisms for any potentially varying VOC.

In this context, Taiwan and Mainland China are selected for comparison. Previous studies on these two societies are conducted in separate analyses with consistent findings (Zheng et al. 2005; Yi et al. 2008). But the two datasets have never been compared directly. We assume that the interplay between cultural homogeneity and political/social heterogeneity produce important effects on the value of having or not having children. In other words, although Chinese cultural heritage emphasizes the positive function of having children, the economic advancement in Taiwan as 
well as the national policy in Mainland China may result in identical values of not wanting (more) children. In addition, to respond to the important research objective of the second VOC study, the value of having or not having children is presumed to reveal intergenerational transmission across three generations. Given the strong endorsement and actual practice of three-generational households in Chinese societies (Yi/Chang 2008; Chang/Yi 2006), the subject above is of particular salience to Taiwan and Mainland China.

Hence, there are three major research issues to be explored in this paper:

(1) Derive Factor Structure of VOC in Taiwan and Mainland China Both positive and negative dimensions of VOC will be investigated, and the factor structure across grandmothers, mothers and teenagers will be compared. Owing to the normative expectations and practices, an attempt will be made to derive meaningful and parsimonious dimensions of VOC for contemporary Chinese families across the strait.

(2) Explore the Intergenerational Transmission among Three Generations While grandmothers and mothers have completed their fertility behaviour, their VOC expressed are regarded to represent their general attitudes toward children's utility. Since fertility-related experiences occur in the private domain, it is thus more likely that mothers' generation resemble the grandmoth-

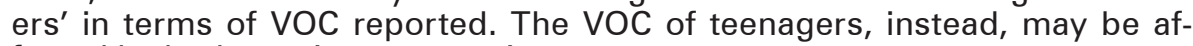
fected by both previous generations.

(3) Identify Mechanisms Accounting for Intergenerational Transmission of VOC From a structural standpoint, social class often indicated by the educational level and differences in the rural-urban background have been suggested to have pronounced effects on the VOC of an individual. Gender is another salient factor differentiating the varying VOC reported.

In brief, this paper will first explore structural components of a positive and negative VOC for Taiwan and China. After controlling for structure, patterns of an intergenerational transmission of VOC among three generations for both Taiwanese and Chinese samples will be delineated. Lastly, potential effects from structural variables such as gender, social class and rural or urban residence will be controlled for to ascertain their influence on the intergenerational transmission of VOC in two Chinese societies.

\section{$3 \quad$ VOC in Taiwan and Mainland China}

Taken from Hoffman and Hoffman's (1973) cross-national studies, fertility decisions are determined by economic, normative and psychological factors. Similarly, fertility intentions are contended to be the outcome of physical, social and emotional factors (Nauck 2010). The significant contribution of the value scheme proposed by Hoffman and Hoffman is that not only the positive value of having children as well as the negative value of not wanting children are incorporated but underlying cultural factors are also considered (Arnold et al. 1975). In cross-societal comparisons, cultural differences have shown to have strong effects on the varying VOC expressed. For example, the son preference or the desire for continuation of the 
family name has been documented to maintain its strength, despite the modernisation processes in many parts of the world (Filmer et al. 2008). The VOC study also confirms that son preference remains a strong predictor for a positive value of children among East Asian families, regardless of their recent rapid economic progress (Trommsdorff/Kornadt 2003). On the other hand, studies point out that the material or economic value of children often exceeds the traditional psychological reward of having children as a symbol of honour, especially in kinship-based societies (Nauck 2007). It is therefore important to examine potential effects of cultural norms on the VOC.

This study intends to delineate whether the cultural norm or the individual resources generate greater influence on the value of having children or not. It is contended that the practice of co-residence and frequent interaction among three generations produce enduring effects and the intergenerational transmission of VOC may become more evident among the Chinese compared to their Western counterpart. In this line of thought, comparing Taiwan and Mainland China allows us to explore the effect on the VOC within similar cultural backgrounds when, however, societal advancement and political systems vary. Specifically, the comparative analysis will shed light on the potential differentiation of the $\mathrm{VOC}$ to be explained by various structural factors.

\subsection{The context of Taiwan}

Taiwan was one of the six countries which participated in the first VOC study in the early 1970s. The original report by $W u$ (1977) pointed out that besides the consensus on the emotional value, the most important positive and negative VOC are continuing the family name and the respective financial cost. Further analyses using the same dataset support the significance of the linkage between ancestors and the future generation in the construct of VOC among married women between the age of 20 to 44 (Thornton et al. 1994). In other words, the social or normative benefit of having children (or to be more precisely, a son) was undoubtedly the crucial reason for having children in Taiwan at that time.

Since the external circumstances have changed from overpopulation to underpopulation over the last three decades, the second VOC study adds a focus on the intergenerational transmission of values placed on children (Trommsdorff/Nauck 2005). Accordingly, the second VOC study in Taiwan has two research concerns: to compare findings with those of the early 1970s and to compare the current VOC with other participating countries (Yi et al. 2008).

To generate corresponding datasets, three surveys on adolescents, their mothers and grandmothers had been conducted from winter 2005 until summer 2007. While most core questions and instruments from the questionnaire of the second VOC project were utilised, the Taiwanese research team also included items from the first VOC study as well as relevant questions on important family dynamics within the Chinese context (e.g., the interaction between mother-in-law and daughterin-law on childbearing and -rearing). Furthermore, in order to derive a meaningful comparison with the first VOC study in Taiwan, we decided to replicate a similar 
sampling design and expand it to larger metropolitan areas. To be specific, the first VOC study was done on urban middle class and urban labour class subjects in Taipei (the capital city) as well as rural samples in Yun-Lin and Chia-Yi (central Taiwan) in order to be able to analyse social class effects and rural urban variation. In 2005, similar administrative units were selected to achieve an expansion to adjacent areas. Furthermore, two metropolitan areas in central (Taichung) and southern (Kaohsiung) Taiwan were added to our sampling frame with social class and rural urban variation remaining as selection criteria (see Fig. 1).

Fig. 1: Sampling areas of the VOC study in Mainland China (left) and Taiwan (right)
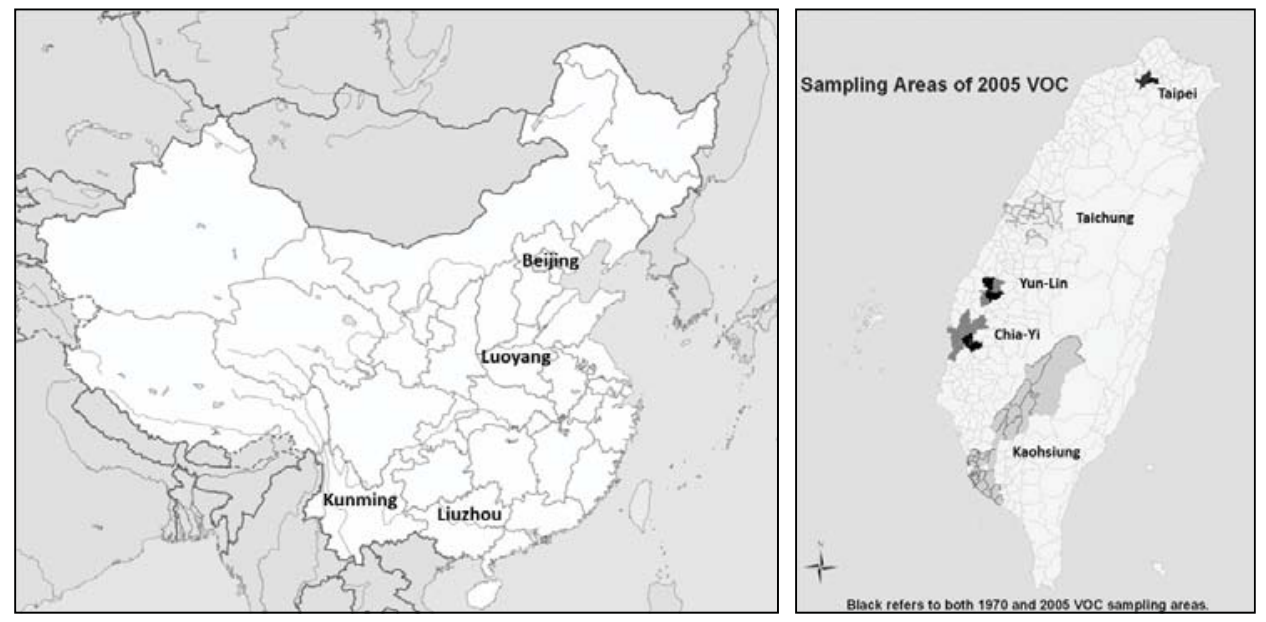

Source: Own design

For the Taiwanese adolescent sample, a total of 1211 first-year students in senior high schools (with an average age of 16 years) were interviewed in 2005. The survey of mothers ended with a response rate of less than 70 percent, or a total of 815 valid responses. But we encountered difficulties in locating grandmothers because married daughters do largely not co-reside with their own mothers. Instead, the major family obligation is directed toward the husband's parents in the Taiwanese context (Chien/Yi 2001; Chien 2001; Yang/Chen 2002; Freedman et al. 1994). Concerning the normative authority held by mothers-in-law over their daughters-in-law's role performance (including bearing sons), we decided to interview paternal grandmothers as well if maternal grandmothers could not be accessed. After laborious and persistent contacts, 347 grandmothers completed the questionnaires, of whom 87 were paternal grandmothers. A total of 260 three-generation triads were thus collected in the Taiwan study.

For the Taiwanese adolescent sample, previous analysis showed that three dimensions are extracted for both a positive as well as a negative VOC with the emo- 
tional value rated the most important followed by the physical and social value ( $\mathrm{Yi}$ et al. 2008). As expected, the physical and social value of having children or not is significantly affected by social class and the rural-urban background. Specifically, urban middle-class teenagers are more likely to rate the importance of children's physical and social value as lower, while urban teenagers as a whole tend to report the negative value of physical constraints as a reason for not wanting children (Yi et al. 2008). In the research framework of Taiwan's VOC study, we added contextual social factors such as network support from friends, community attachment and media exposure which are presumed to influence the formation of the VOC. The results confirm that social context does contribute to the positive value of children among Taiwanese teenagers. The results thus suggest considering the familial, peer and societal influence on individual's VOC (Yi et al. 2008).

\subsection{The context of Mainland China}

Research loci of Mainland China's VOC study are composed of four areas, namely Beijing, Luoyang, Kunming and Liuzhou covering both urban and rural areas (see Fig. 1). In particular, the Beijing sample has included so-called floating population, which refers primarily to migrants in China without local household registration status through the Chinese Hukou system. Among the 1235 respondents are 312 mothers and their teenage children who completed the questionnaires and 209 grandmothers were interviewed, resulting in a total of 209 three-generation triads in the Chinese data set. It should be noted that Mainland China's one-child policy imposes a strong effect on urban areas where 90 percent of families only have one child. In contrast, less than 20 percent of rural families and 22.5 percent of respondents representing floating population have one child. The actual fertility rates clearly vary by the respective geographical background in Mainland China, as reported by several studies (Hsu 1985; Hardee-Cleaveland/Banister 1988; Zheng et al. 2004; Zheng et al. 2005).

Previous findings have shown that all three generations agree that the emotional benefit is the most important reason for having a child (Zheng et al. 2005). On the other hand, the one child policy is, as expected, reported as the most important reason for not wanting more children, followed by worrying about the child's future. Among the rural and floating samples, the financial support received from children in old age is considered the most important factor explaining the positive VOC (Zheng et al. 2005). The lack of social insurance coverage is hence proposed to be the underlying reason. As to patterns of intergenerational transmission, data from Mainland China point out that economic benefits as well as social reward of a positive VOC reveal clear value transmission between grandmothers and mothers.

However, an important issue emerged from Mainland Chinese reports: it is a different labelling rather than a different construct that is used repeatedly. To be specific, the Chinese VOC was initially labelled with substantial, emotional and familial components (Zheng et al. 2005). Zheng and Shi (2006) suggested in another related essay that the labels proposed by Nauck and Klaus (2007), namely comfort, affect and esteem, may be replaced by social/economic, emotional and familial in 
the Chinese context. By doing so, Zheng and Shi actually introduced a new familial dimension into the original construct where physical (corresponding to economic or comfort), emotional (corresponding to affect or psychological), and social (corresponding to normative or esteem) have been distinguished for both positive and negative VOC (Hoffman/Hoffman 1973; Nauck/Claus 2007; Yi et al. 2008).

It should be noted that the inconsistent terminology used in previous studies does not necessarily imply different constructs. Instead, unlike the varying invented labels resulting from factor analyses, the VOC construct may actually be quite similar across different studies. Nevertheless, the very fact that different labels continue to appear suggests a potential need to search for the best fitting construct of VOC for different cultural regions (Trommsdorff/Nauck 2005). In this regard, the comparison between Mainland China and Taiwan offers a current example to show that different labels or even constructs may be suitable for analyses within similar cultures, in contrast to the effort to derive general labels for studies across cultures.

Due to the salience of family values in the Chinese setting, we agree with Zheng and Shi that different combinations of items or different components may explain the Chinese VOC better. However, there are at least two potential problems that need to be addressed. First, there is the relative status of the familial dimension. Since the family value of having children partially coincides with the social reward in VOC, the difference between the social standing of being parents and the family norm of having descendants may not be distinct enough. Secondly, if social and economic dimensions are treated within the same category as producing physical comfort to parents, and if social and familial values may be grouped together (as stated above), then the underlying proposition suggests that there may be only two dimensions of VOC (Kagitcibasi 2007). The argument of two dimensions was actually initiated by Trommsdorff and Nauck with a proposition of two components of VOC: the economic/utilitarian and the psychological/emotional dimension (2005: 11). However, we suspect that a traditional dimension incorporating both the economic/utilitarian value and the social value of having children may prevail among different Chinese societies. Further analyses are thus required to confirm whether our suspected outcome is valid.

\subsection{Research proposition}

Hence, we propose that there may be common core VOC components in two Chinese family systems. But the specific constituents are likely to be different from their Western counterpart and they may also be different for positive and negative VOC. Given the strong family norms on the son preference and on economic support given to elderly parents (Löfstedt et al. 2004; Yi/Chang 2008; Logan et al. 1998; Tseng et al. 2006), familial aspects need to be incorporated into the Chinese VOC construct. Furthermore, the emotional reward or the commitment toward family lineage among the Chinese may very well mix with the social expectations of being parents or having descendants which requires further delineation. For the negative VOC, we suspect that different dimensions unlike the positive VOC may be derived. Powerful reasons for not having children such as balancing work and family roles, 
the changing image of parenthood and large families, as well as the costs of losing personal freedom or the worry about children's future arise from contemporary society. While they may pertain to economic or to psychological aspects, these concerns actually represent realistic constraints in contemporary society which prevent people from wanting to have children. In other words, it is likely that the traditional economic or physical costs along with the psychological constraint of having children fall into the same dimension in contrast to the familial or social demands of becoming parents.

In brief, we propose that different VOC components may be derived for the two Chinese societies (Taiwan and Mainland China) and may vary depending on the positive versus the negative VOC construct. In this paper, delineation of the appropriate factor structure of VOC in Taiwan and in Mainland China will be the first aim of analyses. It is possible that the conventional economic, emotional and social dimensions may reveal various linkages given the particular cultural and normative background in these two Chinese societies (Trommsdorff et al. 2002). Furthermore, the salience of family values may correspond to the social expectations and cultural aspects of VOC may thus be reflected by familial/social components. Since both grandmothers and mothers have completed their fertility behaviours, we suspect, regarding the intergenerational transmission of $\mathrm{VOC}$ among three generations, that there will be stronger association between the VOC of the two older generations, followed by the influence from mothers to teenagers.

\section{$4 \quad$ Data, measurements and methods}

\subsection{Data}

To investigate similarities and differences of VOC and patterns of intergenerational transmission between Taiwan and Mainland China, three-generation samples of both societies will be used for the analyses. 9 and 22 triads are excluded from the original 260 and 209 triads in Taiwan and Mainland China because of missing data on the VOC instrument or education. Descriptive statistics of the two samples are presented in Table 1. Both samples consist of similar birth cohorts making up the three generations under investigation. This adds to our confidence in conducting the comparative study without being confronted with a possible cohort effect. In terms of education, the mean years of schooling are similar for the two grandmothers' samples. But Taiwanese mothers with teenage children have in general spent significantly more years in education and achieved higher educational levels than their Chinese counterparts. With regard to the distribution of residence, the Chinese sample is constituted by 52 percent of rural residents as compared to 34 percent of rural respondents in the Taiwanese sample. 
Tab. 1: Descriptive statistics of Taiwan and Mainland China samples in the VOC study

\begin{tabular}{lrrrrrr}
\hline & & Taiwan & & \multicolumn{3}{c}{ Mainland China } \\
& Grandma & Mother & Adolescent & Grandma & Mother & Adolescent \\
\hline Sample size & 260 & 816 & 1211 & 209 & 312 & 312 \\
$\quad$ 3-generation triad & & $251^{*}$ & & & $187^{*}$ & \\
Range of birth year & $1922-53$ & $1950-75$ & $1988-90$ & $1920-50$ & $1951-72$ & $1983-91$ \\
Median year of birth & 1936 & 1962 & 1990 & 1936 & 1964 & 1989 \\
Mean year of schooling & 3.5 & 12.1 & - & 3.9 & 9.8 & - \\
Educational level (in \%) & & & & & & \\
$\quad$ No schooling & 45.4 & 0 & - & 38.5 & 0.5 & - \\
$\quad$ Primary & 36.9 & 13.1 & - & 33.7 & 12.8 & - \\
$\quad$ Secondary & 10.4 & 26.1 & - & 20.3 & 62.6 & - \\
$\quad$ Vocational college & 6.2 & 33.1 & - & 6.4 & 14.5 & - \\
$\quad$ University and above & 1.1 & 27.7 & - & 1.1 & 9.6 & - \\
Rural Residency & & $34 \%$ & & & $52 \%$ & \\
\hline
\end{tabular}

* There are 260 and 209 triads in the Taiwanese and Mainland Chinese samples respectively. 9 and 22 triads in each sample were excluded from analysis because reports on VOC items or education are missing.

Source: Own calculations

\subsection{Measurements: Value of children (VOC) scales}

All respondents were asked to rate reasons for wanting a child and reasons for not wanting a child. Two VOC instruments, namely the positive VOC and the negative VOC, were utilized, comprising selections of original items from the first VOC study in the 1970s (Arnold et al. 1975), items from the Family and Fertility Survey conducted by the UNECE, and a few newly developed items by a German research team (Trommsdorff/Nauck 2005). It should be noted that the VOC instrument was not identical in all subsamples. The original mothers' questionnaire includes 27 items for positive VOC and 21 items for negative VOC. The items used for interviewing mothers were modified for both grandmothers' and adolescents' questionnaires. For grandmothers, the total number of items about wanting a child was reduced to 23 items and questions on reasons for not wanting a child were cut to 14 items. Since adolescents do not have fertility experience yet, the list of items was reduced further to 18 for positive VOC and 13 items for negative VOC.

All the VOC instruments and questionnaires were directly translated and implemented in Mainland China's VOC study. A different approach was taken in Taiwan. The complete VOC scale from the mothers' questionnaire served as the baseline. After the pilot study, only 16 positive VOC items and 14 negative VOC items were retained with slight modifications of wording in the three Taiwanese questionnaires. To conduct a comparative study on the VOC, 14 items listing reasons for wanting a 
child (Table 2) and 9 items for not wanting a child (Table 6) were used in the samples from Taiwan and Mainland China in the following analyses. The detailed description and comparison with regard to specific items are presented in the next section.

\subsection{Methods}

It has been a common practice to establish equivalent or comparable measurements of relevant constructs across cultures in cross-cultural studies. A variety of methods have been introduced for assessing equivalent forms of cultural measurements. For instance, in major psychological studies, the principal components or factor analysis are adapted to assess metric equivalence of the scales and instruments. Factor solutions have been expanded to include congruence/proportionality coefficients for assessing structural equivalence across cultures (van de Vijver) Leung 1997).

Using data from 11 countries involved in the VOC replication study in 2002 and 2003, Nauck and Klaus (2007) have attempted to establish the cross-national equivalence for the positive VOC measurement. As a result, 12 items for wanting a child were selected and among them, a three-dimensional solution comprising comfort, affect, and esteem was generated for further analyses. Since there are fewer VOC items to begin with in the Taiwan-Mainland China comparative study, another strategy to find an appropriate factor solution was adopted. Using the covariance structural modelling or confirmatory factor analysis (CFA) to test for equivalence has been proposed in the literature (Jones-Farmer et al. 2008; Kankaraš/Moors 2009). Hence, a combination of exploratory and confirmatory factor analyses was carried out for assessing the structural equivalence of VOC dimensions in Taiwan and Mainland China.

Before exploring the intergenerational transmission of VOC, confirmatory factor analyses to further evaluate whether grandmothers and mothers share equivalent factor structures on VOC were performed. According to the goodness-of-fit statistics for an invariance test, ${ }^{1}$ we can assume that grandmothers and mothers from Mainland China share a similar factor structure on reasons for wanting a child. But the variation on the VOC construct between grandmothers and mothers from Taiwan does not produce similar results. It should be noted that by pooling grandmothers' and mothers' samples from Taiwan and Mainland China, our analyses find that only the negative VOC has an identical structural factor solution available for conducting a cross-cultural comparison. The factor solutions of positive VOC are shown to be different between the Taiwanese and Mainland samples. Possible interpretations regarding different factor solutions for both positive and negative VOC are provided in the next section.

1 To simplify the article context, we decide to report the invariance testing results of confirmatory factor analyses as follows: the positive VOC $\left(\Delta \mathrm{X}^{2}=91.11, d f=14, p<.001\right)$ and the negative VOC $\left(\Delta \mathrm{X}^{2}=35.93, d f=14, p<.001\right)$ between Taiwanese mothers and grandmothers; the positive VOC $\left(\Delta \mathrm{X}^{2}=35.93, d f=9, .01>p>.05\right)$ and the negative VOC $\left(\Delta \mathrm{X}^{2}=11.13, d f=9, p>.05\right)$ between mothers and grandmothers from Mainland China. 


\section{$5 \quad$ Empirical results}

\subsection{Positive value of children}

All respondents were asked to rate the importance of a variety of reasons for wanting a child on a 5-point scale ranging from "not important at all" (score 1) to "very important" (score 5). The means of ratings of the 14 items of positive VOC and the results of the $t$-test between samples from Mainland China and Taiwan are presented in Table 2. It is evident that some reasons for wanting a child are considered important to all three generations in these two Chinese societies (items 2, 8, 9, 22). Grandmothers are more likely to emphasize the importance of economic utilitarian $(12,21,27)$ and social/familial reasons $(17,20,25)$. For instance, the items "to carry on the family name" (20) and "to have someone to help the family economically" (21) reveal significant generational preference among grandmothers in contrast to the younger generations.

On the contrary, mothers' concerns seem to centre around the emotional benefits of parenthood as well as their own self-realisation, e.g. "it's fun to have young children around the house" (8), "watching children grow" (9), "making family important or complete" (2), and "increasing the sense of responsibility" (5). In general, Mainland mothers in comparison to Taiwanese mothers tend to rate the emotional dimensions with higher scores. As to economic or old-age security dimensions (e.g. 21 and 27), mothers are likely to indicate less strong endorsement compared to grandmothers. For the youngest generation greater emphasis appears to be placed on the emotional reward of having children $(5,8,9,13)$ while lower scores are given in general. As to economic reasons, teenagers in the two research settings do not rate their importance as high $(21,27)$, but the youth in Mainland China reports even lower scores. The most vivid decrease in positive VOC dimensions among the three generations pertains to the normative or family items, including "parenthood improves mother's standing and reputation among her kin" (11), "to carry on the family name" (20), and "duty to have children" (25). In other words, the positive VOC among grandmothers, mothers and teenagers reveals expected generational differences in the conventional economic, emotional and social dimensions. The traditional family value of having children clearly receives greater support among grandmothers followed by mothers and the weakest support among teenagers.

Table 3 shows the result of the factor solution and internal consistency tests regarding the positive VOC. By carrying out exploratory factor analyses, two slightly different two-factor solutions, traditional and emotional, are derived for both threegeneration samples in Taiwan and Mainland China. Similar as VOC findings from India, the traditional factor incorporates both the economic as well as the social reward of having children (Mishra et al. 2005). In addition, it should be noted that three items, namely (2) "new family member makes family more complete/important", (17) "life will be continued through your children" and (25) "it's a duty to have children according to belief" fall into different dimensions for Taiwan and Mainland China. To better capture the meaning of the value of children in the Chinese context, the term of "important" in item (2) is substituted by "complete" in the Taiwan ques- 
The Intergenerational Transmission of the Value of Children $\quad 691$

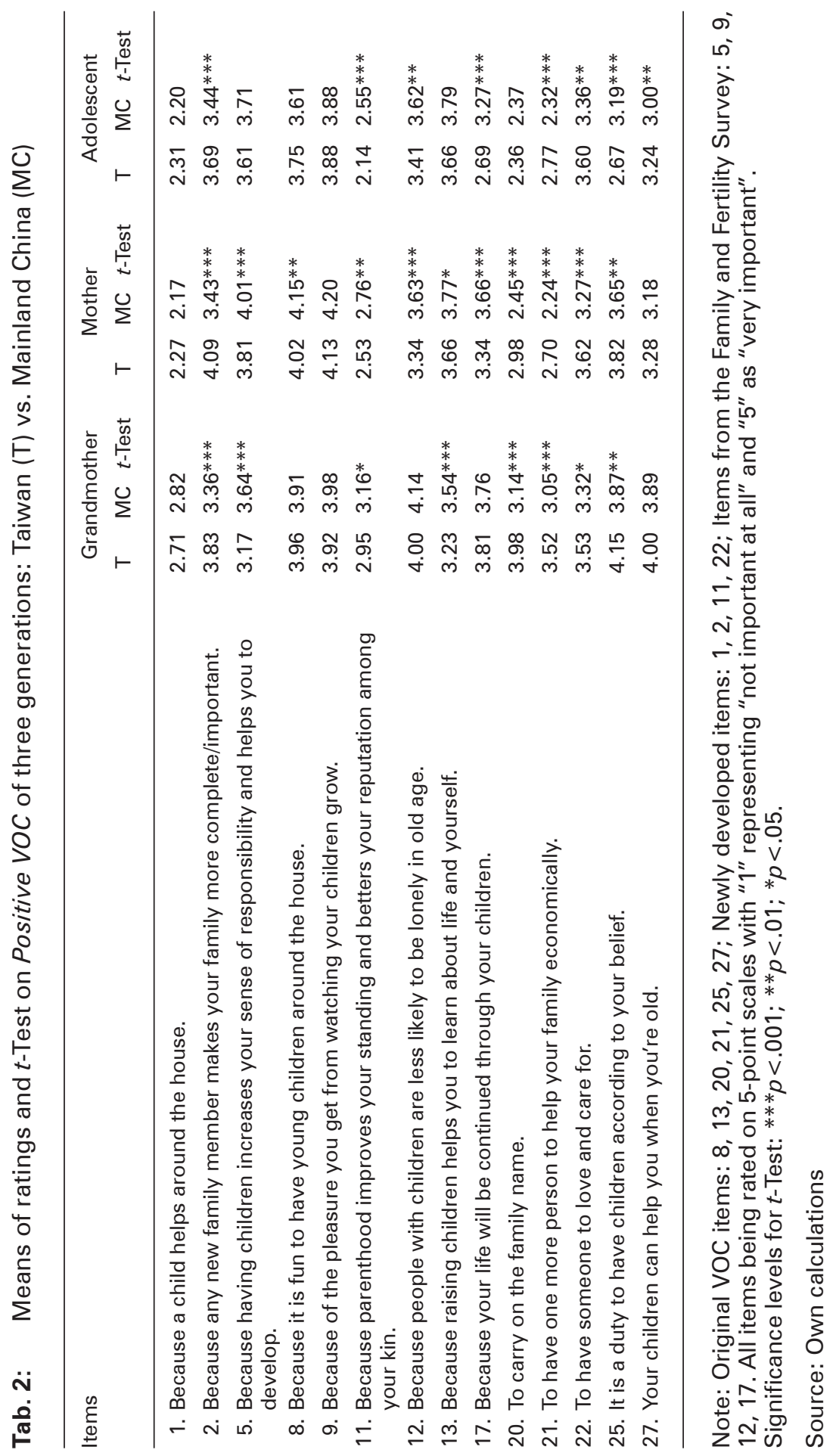


Tab. 3: Factor solutions and internal consistency of Positive VOC: Taiwan vs. Mainland China

\begin{tabular}{|c|c|c|c|}
\hline & Grandma & Mother & Adolescent \\
\hline \multicolumn{4}{|l|}{ Taiwan } \\
\hline \multicolumn{4}{|l|}{ Traditional VOC } \\
\hline 1. Because a child helps around the house. & 0.4431 & 0.5223 & 0.5749 \\
\hline $\begin{array}{l}\text { 11. Because parenthood improves your standing and betters your } \\
\text { reputation among your kin. }\end{array}$ & 0.3787 & 0.6001 & 0.6577 \\
\hline 12. Because people with children are less likely to be lonely in old age. & 0.6903 & 0.6444 & 0.5459 \\
\hline 17. Because your life will be continued through your children. & 0.6836 & 0.7420 & 0.5267 \\
\hline 20. To carry on the family name. & 0.6385 & 0.7501 & 0.6863 \\
\hline 21. To have one more person to help your family economically. & 0.6710 & 0.7726 & 0.7920 \\
\hline 25. When it is a duty to have children according to your belief. & 0.5147 & 0.5246 & 0.3964 \\
\hline 27. Your children can help you when you're old. & 0.6787 & 0.7235 & 0.6385 \\
\hline Cronbach's a coefficient & 0.80 & 0.86 & 0.83 \\
\hline \multicolumn{4}{|l|}{ Emotional VOC } \\
\hline $\begin{array}{l}\text { 2. Because any new family member makes your family more complete. } \\
\text { 5. Because having children increases your sense of responsibility and }\end{array}$ & 0.7964 & 0.5735 & 0.7066 \\
\hline helps you to develop. & 0.7118 & 0.5437 & 0.8059 \\
\hline 8. Because it is fun to have young children around the house. & 0.8193 & 0.7906 & 0.8559 \\
\hline 9. Because of the pleasure you get from watching your children grow. & 0.8146 & 0.6424 & 0.7789 \\
\hline 13. Because raising children helps you to learn about life and yourself. & 0.7361 & 0.4016 & 0.6909 \\
\hline 22. To have someone to love and care for. & 0.7648 & 0.3365 & 0.5597 \\
\hline Cronbach's a coefficient & 0.90 & 0.72 & 0.88 \\
\hline \multicolumn{4}{|l|}{ Mainland China } \\
\hline \multicolumn{4}{|l|}{ Traditional VOC } \\
\hline 1. Because a child helps around the house. & 0.5058 & 0.5455 & 0.5968 \\
\hline $\begin{array}{l}\text { 2. Because any new family member makes your family more important. } \\
\text { 11. Because parenthood improves your standing and betters your }\end{array}$ & 0.4715 & 0.4906 & 0.5465 \\
\hline reputation among your kin. & 0.4045 & 0.5286 & 0.6877 \\
\hline 12. Because people with children are less likely to be lonely in old age. & 0.5941 & 0.4686 & 0.6448 \\
\hline 20. To carry on the family name. & 0.6604 & 0.7055 & 0.7065 \\
\hline 21. To have one more person to help your family economically. & 0.7449 & 0.6952 & 0.7383 \\
\hline 27. Your children can help you when you're old. & 0.7979 & 0.6058 & 0.7822 \\
\hline Cronbach's $\alpha$ coefficient & 0.77 & 0.79 & 0.80 \\
\hline \multicolumn{4}{|l|}{ Emotional VOC } \\
\hline $\begin{array}{l}\text { 5. Because having children increases your sense of responsibility and } \\
\text { helps you to develop. }\end{array}$ & 0.5377 & 0.5699 & 0.7130 \\
\hline 8. Because it is fun to have young children around the house. & 0.6861 & 0.7060 & 0.7775 \\
\hline 9. Because of the pleasure you get from watching your children grow. & 0.7279 & 0.7628 & 0.8109 \\
\hline 13. Because raising children helps you to learn about life and yourself. & 0.6307 & 0.6610 & 0.7673 \\
\hline 17. Because your life will be continued through your children. & 0.5335 & 0.5312 & 0.5685 \\
\hline 22. To have someone to love and care for. & 0.5407 & 0.6278 & 0.7409 \\
\hline 25. When it is a duty to have children according to your belief. & 0.3832 & 0.5426 & 0.6316 \\
\hline Cronbach's $\alpha$ coefficient & 0.82 & 0.79 & 0.85 \\
\hline
\end{tabular}

\section{Source: Own calculations}

tionnaire. In fact, this particular item has been repeatedly included in major Taiwan social surveys since 1985. We suspect that the wording itself (e.g., make your family more complete versus important) brings different perceptions for respondents in 
Tab. 4: $\quad$ Mean scores of Two Positive VOC dimensions

\begin{tabular}{|c|c|c|c|c|c|c|}
\hline \multirow[b]{2}{*}{ Factor Dimension } & \multicolumn{3}{|c|}{ Taiwan } & \multicolumn{3}{|c|}{ Mainland China } \\
\hline & Grandma & Mother & Adolescent & Grandma & Mother & Adolescent \\
\hline Traditional VOC & 3.33 & 2.85 & 2.74 & 3.64 & 3.06 & 2.63 \\
\hline \multicolumn{7}{|l|}{ Residency } \\
\hline Urban & $2.99 * * *$ & $2.36^{* * *}$ & $2.41 * * *$ & $3.56 * *$ & $2.83 * * *$ & $2.53^{* *}$ \\
\hline Rural & 3.64 & 3.31 & 3.04 & 3.80 & 3.51 & 2.84 \\
\hline \multicolumn{7}{|l|}{ Education } \\
\hline No schooling & 3.83 & -- & - & 3.52 & 3.86 & - \\
\hline Primary & 3.58 & 3.49 & - & 3.44 & 3.43 & - \\
\hline Secondary & 3.32 & 3.27 & - & 3.02 & 2.96 & - \\
\hline Vocational college & 3.30 & 3.01 & - & 2.77 & 2.26 & - \\
\hline University and above & 2.83 & 2.64 & - & 2.07 & 2.20 & - \\
\hline \multicolumn{7}{|l|}{ Sex of adolescent } \\
\hline Boy & - & - & 2.87 & - & - & $2.78 * *$ \\
\hline Girl & - & - & 2.65 & - & - & 2.50 \\
\hline Emotional VOC & 3.70 & 3.86 & 3.51 & 3.61 & 3.95 & 3.65 \\
\hline \multicolumn{7}{|l|}{ Residency } \\
\hline Urban & 3.63 & $3.73^{* *}$ & $3.34^{*}$ & $3.70 * *$ & 3.98 & 3.61 \\
\hline Rural & 3.76 & 3.97 & 3.67 & 3.43 & 3.89 & 3.74 \\
\hline \multicolumn{7}{|l|}{ Education } \\
\hline No schooling & 3.60 & -- & - & 3.66 & 4.00 & - \\
\hline Primary & 3.54 & 3.79 & - & 3.75 & 4.04 & - \\
\hline Secondary & 3.54 & 3.88 & - & 3.62 & 3.82 & - \\
\hline Vocational college & 4.20 & 4.07 & - & 3.86 & 3.85 & - \\
\hline University and above & 4.17 & 3.93 & - & 4.07 & 3.82 & - \\
\hline \multicolumn{7}{|l|}{ Sex of adolescent } \\
\hline Boy & - & - & 3.58 & - & - & 3.68 \\
\hline Girl & - & - & 3.46 & - & - & 3.63 \\
\hline
\end{tabular}

Note: $t$-Test: rural-urban and sex differences; ANOVA: educational difference Significance level: ${ }^{* *} p<.001 ;{ }^{* *} p<.01 ;{ }^{*} p<.05$

Source: Own calculations

the two Chinese societies. "Life being continued through children", as well as "one's duty to bear children" may be considered salient social expectations in Taiwan but they lead to important emotional satisfaction in Mainland China. Despite these differences, the alpha coefficients for the three generations in both Mainland China and Taiwan indicate an overall high internal consistency within factors.

A related concern is to examine the differences between generations as well as to ascertain various social strata on the VOC dimensions. The mean scores of two dimensions in Table 4 show that the emotional reward of having children receives overwhelming support, particularly among mothers (3.86 for Mainland China and 3.95 for Taiwan). In contrast, the traditional benefits of having children not only have lower scores, but also demonstrate a gradual decrease by generations in both 
Tab. 5: Correlation coefficients of Positive VOC across generations, Mainland China (in bold) and Taiwan (grey-shaded)

\begin{tabular}{|c|c|c|c|c|c|c|}
\hline & Tra_G1 & Emo_G1 & Tra_G2 & Emo_G2 & Tra_G3 & Emo_G3 \\
\hline \multicolumn{7}{|c|}{ All sample } \\
\hline Tra_G1 & 1.00 & $0.40 * * *$ & $0.45 * * *$ & $0.25 * * *$ & $0.31 * * *$ & 0.09 \\
\hline Emo_G1 & $0.45^{* * *}$ & 1.00 & $0.18 *$ & $0.29 * * *$ & 0.11 & 0.07 \\
\hline Tra_G2 & $0.20 * * *$ & $-0.14^{*}$ & 1.00 & $0.31 * * *$ & $0.38 * * *$ & $0.24 * * *$ \\
\hline Emo_G2 & 0.01 & 0.07 & $0.26 * * *$ & 1.00 & 0.10 & $0.13 *$ \\
\hline Tra_G3 & 0.10 & -0.04 & $0.13^{*}$ & -0.04 & 1.00 & $0.65 * * *$ \\
\hline Emo_G3 & -0.03 & -0.01 & 0.04 & $0.12^{*}$ & $0.44 * * *$ & 1.00 \\
\hline \multicolumn{7}{|c|}{ Urban sample } \\
\hline Tra_G1 & 1.00 & $0.33 * *$ & $0.28 * *$ & 0.13 & $0.33 * *$ & 0.11 \\
\hline Emo_G1 & $0.53^{* * *}$ & 1.00 & $0.31 * *$ & 0.18 & 0.14 & 0.18 \\
\hline Tra_G2 & $0.16^{*}$ & $-0.03^{*}$ & 1.00 & 0.13 & $0.29 * *$ & $0.24 *$ \\
\hline Emo_G2 & 0.06 & 0.09 & $0.38 * * *$ & 1.00 & 0.06 & 0.14 \\
\hline Tra_G3 & 0.08 & -0.01 & 0.07 & 0.05 & 1.00 & $0.73 * * *$ \\
\hline Emo_G3 & -0.04 & 0.02 & 0.03 & 0.14 & $0.47^{* * *}$ & 1.00 \\
\hline \multicolumn{7}{|c|}{ Rural sample } \\
\hline Tra_G1 & 1.00 & $0.46 * * *$ & $0.20 *$ & $0.22 * *$ & -0.05 & -0.16 \\
\hline Emo_G1 & $0.36 * * *$ & 1.00 & 0.03 & $0.36 * * *$ & -0.01 & -0.12 \\
\hline Tra_G2 & 0.10 & $-0.21 *$ & 1.00 & $0.33 * * *$ & 0.12 & 0.10 \\
\hline Emo_G2 & -0.06 & -0.03 & 0.19 & 1.00 & -0.01 & 0.04 \\
\hline Tra_G3 & 0.06 & -0.02 & 0.02 & -0.16 & 1.00 & $0.50 * * *$ \\
\hline Emo_G3 & -0.08 & -0.05 & -0.04 & 0.11 & $0.36 * * *$ & 1.00 \\
\hline
\end{tabular}

Tra: Traditonal VOC; Emo: Emotional VOC

G1: Grandmother; G2: Mother; G3: Adolescent

Significance level: ${ }^{* *} p<.001 ;{ }^{* *} p<.01 ;{ }^{*} p<.05$

Source: Own calculations

research settings. We should point out that for both Taiwan and Mainland China rural samples report much higher traditional scores of positive VOC than their urban counterparts, as do less educated compared to more highly educated respondents. But with regard to emotional VOC, no clear association between educational level and emotional rewards can be ascertained, especially among mothers' samples. For adolescents in Taiwan and Mainland China, the only gender difference was found for men in Mainland China showing stronger support for the traditional value of having children.

To detect a possible value transmission among the three generations, we first look at the correlation coefficients of positive VOC by using the two factors derived 
above, traditional and emotional dimensions. For Mainland samples, Table 5 indicates that except the emotional transmission from grandmothers to their teenage grandchildren, there is a strong link of positive VOC between generations. Significant correlations are found for all three dyads, grandmothers and mothers, mothers and teenagers, and grandmothers and teenagers, on both VOC dimensions. On the other hand, for the Taiwanese samples, value transmission is evident between mothers and their teenage children for both traditional and emotional dimensions and between grandmothers and mothers for the traditional dimension. In contrast, cross-generational transmission between grandmothers and their teenage grandchildren is less likely and does not reach statistical significance in Taiwan. Also, the traditional value of having children appears to receive greater endorsement among all samples in both research settings.

\subsection{Negative value of children}

The negative VOC are constituted by nine items in this study (see Table 6). The overall comparison within each generation indicates that Taiwanese grandmothers are least likely to report negative attitudes toward having children; while patterns of specific reasons for not wanting a child are more similar between mothers in Taiwan and Mainland China. Teenagers do not only express relatively strong negative attitudes but Taiwanese adolescents tend to report more negative concerns than their Mainland counterparts.

With regard to specific reasons for not wanting a child, Table 6 shows that "the uncertain future for children" emerged as the priority concern across all generations in both research settings (12), followed by "worries toward children in illness" (10). In other words, the concern for children's potential hardship serves as the main reason for not wanting a child in both Chinese samples. The difficulties of being parents in contemporary society such as "losing personal freedom" (11) or "difficulty taking care of both family and work" (6) are rated as high negative VOC, too. But motherhood (16) as well as large families (8) both being traditional values receive low ratings which suggest that they are not important reasons for not wanting a child in the Chinese context.

In order to derive appropriate factor structures for negative VOC, steps of analyses similar to those for positive VOC are applied. Unlike the positive VOC dimensions, the same two-factor solution was generated for Taiwan and Mainland China by applying exploratory factor analyses. The results of factor structure and internal consistency of nine negative VOC items are presented in Table 7. The first factor consists of three items: "worrying about children being ill" (10), "loss of personal freedom when becoming parents" (11), and "concern about children's future" (12). Since these items all reflect the psychological and emotional cost of not wanting children, the first factor is labelled as the psychological/emotional constraint of VOC. There are different dimensions in Mainland China, labelled "Physical/Psychological Constraint VOC". The second factor comprises six items including "tensions occurring in interpersonal relations" ( 3 and 15), "in performing family and work roles" (6 and 7), and "in potential conflict with traditional family values" (8 and16) which 
696 - Chin-Chun Yi, Yu-Hua Chen

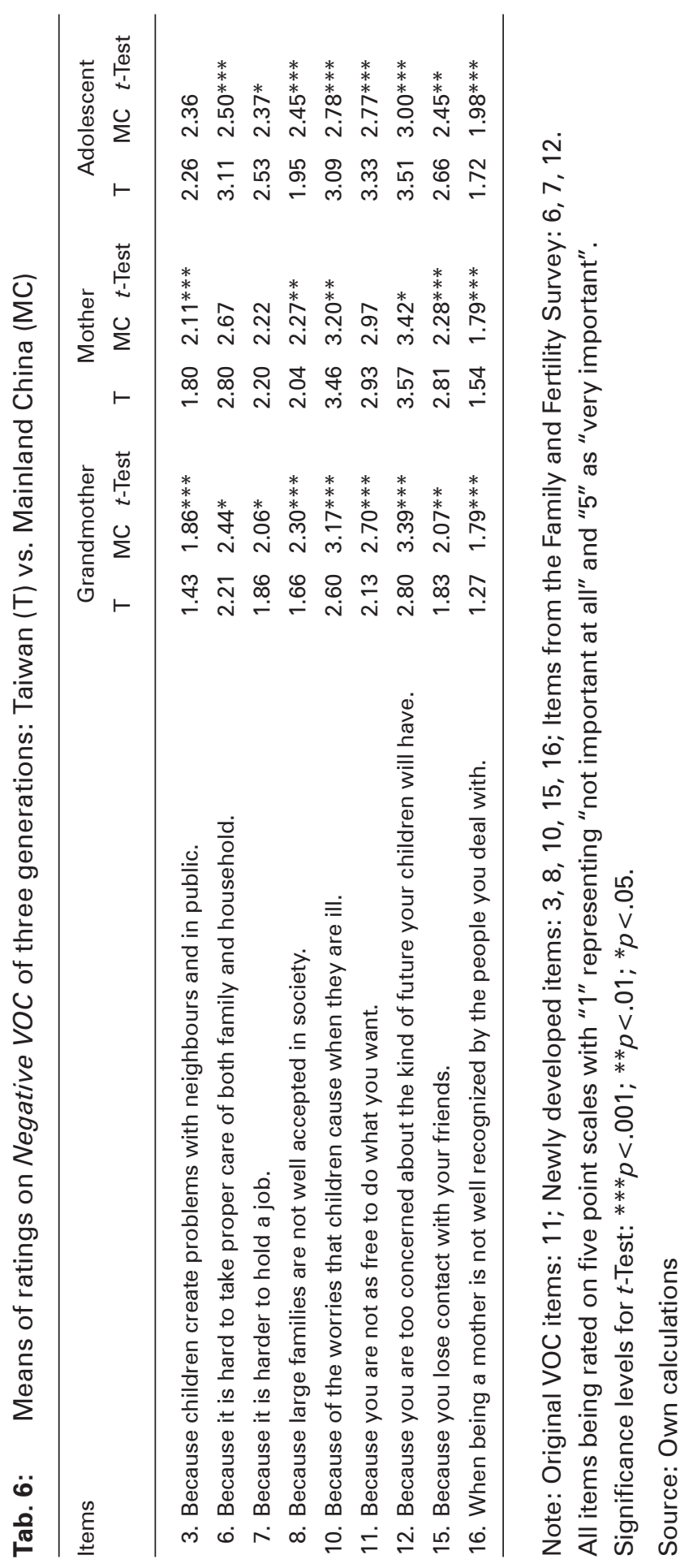


Tab. 7: Factor solutions and internal consistency of Negative VOC: Taiwan vs. Mainland China

\begin{tabular}{|c|c|c|c|}
\hline & Grandma & Mother & Adolescent \\
\hline \multicolumn{4}{|l|}{ Taiwan } \\
\hline \multicolumn{4}{|l|}{ Psychological/Emotional Constraint VOC } \\
\hline 10. Because of the worries that children cause when they are ill. & 0.6680 & 0.6447 & 0.6248 \\
\hline 11. Because you are not as free to do what you want. & 0.7946 & 0.7521 & 0.8053 \\
\hline $\begin{array}{l}\text { 12. Because you are too concerned about the kind of future your children } \\
\text { will have. }\end{array}$ & 0.6544 & 0.7461 & 0.8760 \\
\hline Cronbach's $\alpha$ coefficient & 0.83 & 0.67 & 0.66 \\
\hline \multicolumn{4}{|l|}{ Familial/Social Demand VOC } \\
\hline 3. Because children create problems with neighbours and in public. & 0.4739 & 0.4206 & 0.6939 \\
\hline 6. Because it is hard to take proper care of both family and household. & 0.8124 & 0.7473 & 0.5895 \\
\hline 7. Because it is harder to hold a job. & 0.6830 & 0.6610 & 0.7588 \\
\hline 8. Because large families are not well accepted in society. & 0.4326 & 0.3921 & 0.6797 \\
\hline 15. Because you lose contact with your friends. & 0.7098 & 0.6212 & 0.7489 \\
\hline $\begin{array}{l}\text { 16. When being a mother is not well recognised by the people you deal } \\
\text { with. }\end{array}$ & 0.3578 & 0.2971 & 0.5706 \\
\hline Cronbach's a coefficient & 0.79 & 0.69 & 0.76 \\
\hline \multicolumn{4}{|l|}{ Mainland China } \\
\hline \multicolumn{4}{|l|}{ Physical/Psychological Constraint VOC } \\
\hline 10. Because of the worries that children cause when they are ill. & 0.4493 & 0.4332 & 0.7539 \\
\hline 11. Because you are not as free to do what you want. & 0.7652 & 0.7509 & 0.8499 \\
\hline $\begin{array}{l}\text { 12. Because you are too concerned about the kind of future your children } \\
\text { will have. }\end{array}$ & 0.7032 & 0.7428 & 0.8739 \\
\hline Cronbach's a coefficient & 0.70 & 0.67 & 0.77 \\
\hline \multicolumn{4}{|l|}{ Familial/Social Demand VOC } \\
\hline 3. Because children create problems with neighbours and in public. & 0.6001 & 0.5236 & 0.6910 \\
\hline 6. Because it is hard to take proper care of both family and household. & 0.7163 & 0.7188 & 0.7170 \\
\hline 7. Because it is harder to hold a job. & 0.5628 & 0.5177 & 0.7876 \\
\hline 8. Because large families are not well accepted in society. & 0.3598 & 0.3517 & 0.6853 \\
\hline 15. Because you lose contact with your friends. & 0.5454 & 0.4877 & 0.7129 \\
\hline $\begin{array}{l}\text { 16. When being a mother is not well recognised by the people you deal } \\
\text { with. }\end{array}$ & 0.4158 & 0.4156 & 0.7654 \\
\hline Cronbach's $\alpha$ coefficient & 0.74 & 0.64 & 0.82 \\
\hline
\end{tabular}

\section{Source: Own calculations}

result in not wanting to bear children. Since these items pertain to the familial and social dimension of negative VOC, the second factor is thus labelled as the familial and social demand of VOC. The statistical result points out that while each factor meets the requirement of internal consistency lower alpha coefficients are shown for both mothers' samples in Taiwan and Mainland China.

Table 8 presents the mean scores of the derived two negative VOC dimensions. Overall, the emotional/psychological constraints of having children receive greater endorsement than the familial-social demands of being parents. The comparison of three generations regarding these two dimensions shows that Taiwanese mothers 
Tab. 8: Mean scores of two Negative VOC dimensions

\begin{tabular}{|c|c|c|c|c|c|c|}
\hline & \multicolumn{3}{|c|}{ Taiwan } & \multicolumn{3}{|c|}{ Mainland China } \\
\hline & Grandma & Mother & Adolescent & Grandma & Mother & Adolescent \\
\hline Psychological/Emotional & 2.51 & 3.34 & 3.35 & 3.09 & 3.28 & 2.95 \\
\hline \multicolumn{7}{|l|}{ Residency } \\
\hline Urban & $2.41 *$ & 3.27 & 3.40 & 2.98 & $3.09 * *$ & 2.95 \\
\hline Rural & 2.70 & 3.29 & 3.25 & 3.20 & 3.46 & 2.94 \\
\hline \multicolumn{7}{|l|}{ Education } \\
\hline No schooling & 2.57 & - & - & 3.13 & 2.67 & - \\
\hline Primary & 2.53 & 3.15 & - & 3.18 & 3.35 & - \\
\hline Secondary & 2.15 & 3.36 & - & 2.86 & 3.40 & - \\
\hline Vocational college & 2.58 & 3.39 & - & 3.08 & 3.05 & - \\
\hline University and above & 2.89 & 3.36 & - & 3.50 & 2.83 & - \\
\hline \multicolumn{7}{|l|}{ Sex of adolescent } \\
\hline Boy & - & - & 3.25 & - & - & 3.00 \\
\hline Girl & - & - & 3.44 & - & - & 2.91 \\
\hline Familial/Social Demand VOC & 1.71 & 2.24 & 2.36 & 2.12 & 2.17 & 2.46 \\
\hline \multicolumn{7}{|l|}{ Residency } \\
\hline Urban & 1.73 & 2.21 & 2.39 & $2.25^{*}$ & 2.23 & 2.49 \\
\hline Rural & 1.67 & 2.31 & 2.39 & 2.00 & 2.11 & 2.44 \\
\hline \multicolumn{7}{|l|}{ Education } \\
\hline No schooling & 1.69 & - & - & 2.11 & 2.50 & - \\
\hline Primary & 1.73 & 2.18 & - & 2.04 & 2.09 & - \\
\hline Secondary & 1.66 & 2.33 & - & 2.22 & 2.18 & - \\
\hline Vocational college & 2.00 & 2.23 & - & 2.22 & 2.31 & - \\
\hline University and above & 1.78 & 2.19 & - & 2.17 & 1.97 & - \\
\hline \multicolumn{7}{|l|}{ Sex of adolescent } \\
\hline Boy & - & - & 2.37 & - & - & 2.60 \\
\hline Girl & - & - & 2.35 & - & - & 2.37 \\
\hline
\end{tabular}

Note: $t$-Test: rural-urban and sex differences; ANOVA: educational difference Significance level: ${ }^{* *} p<.001 ;{ }^{* *} p<.01 ;{ }^{*} p<.05$

Source: Own calculations

and teenagers as well as Mainland grandmothers and mothers express more similar attitudes in not wanting children. In addition to the lower concern on the emotional/ psychological constraint of teenagers in Mainland China, a gradual increase in the cost of having children is observed over generations, with older generations reporting lower scores and younger generations reporting higher scores. This means that grandmothers are less bothered by the constraints imposed on being parents than teenagers who express the most negative attitudes on having children, and mothers are in between these two.

In terms of urban-rural differences on negative VOC dimensions, a few significant differences are attained while the general mean score resembles the overall 
Tab. 9: $\quad$ Correlation coefficients of Negative $V O C$ across generations, Mainland China (in bold) and Taiwan (grey-shaded)

\begin{tabular}{|c|c|c|c|c|c|c|}
\hline & PE_G1 & FS_G1 & PE_G2 & FS_G2 & PE_G3 & FS_G3 \\
\hline \multicolumn{7}{|c|}{ All sample } \\
\hline PE_G1 & 1.00 & $0.46 * * *$ & $0.30 * * *$ & $0.21 * *$ & -0.01 & -0.04 \\
\hline FS_G1 & $0.71 * * *$ & 1.00 & $0.15 *$ & $0.39 * * *$ & 0.06 & 0.05 \\
\hline PE_G2 & 0.06 & 0.03 & 1.00 & $0.38 * * *$ & $0.14^{*}$ & 0.04 \\
\hline FS_G2 & 0.04 & -0.01 & $0.61 * * *$ & 1.00 & 0.03 & 0.03 \\
\hline PE_G3 & 0.01 & 0.04 & 0.02 & 0.05 & 1.00 & $0.65 * * *$ \\
\hline FS_G3 & 0.05 & -0.01 & 0.01 & -0.02 & $0.58 * * *$ & 1.00 \\
\hline \multicolumn{7}{|c|}{ Urban sample } \\
\hline PE_G1 & 1.00 & $0.56 * * *$ & 0.12 & $0.22^{*}$ & -0.11 & -0.18 \\
\hline FS_G1 & $0.77 * * *$ & 1.00 & $0.20 *$ & $0.31 * *$ & 0.10 & 0.06 \\
\hline PE_G2 & 0.06 & 0.03 & 1.00 & $0.60 * * *$ & $0.20 *$ & 0.06 \\
\hline FS_G2 & -0.06 & -0.08 & $0.62 * * *$ & 1.00 & 0.15 & 0.03 \\
\hline PE_G3 & 0.01 & 0.04 & 0.09 & 0.06 & 1.00 & $0.72 * * *$ \\
\hline FS_G3 & 0.03 & -0.01 & 0.09 & 0.01 & $0.57 * * *$ & 1.00 \\
\hline \multicolumn{7}{|c|}{ Rural sample } \\
\hline PE_G1 & 1.00 & $0.42 * * *$ & $0.43 * * *$ & $0.23 *$ & 0.09 & 0.12 \\
\hline FS_G1 & $0.60 * * *$ & 1.00 & 0.19 & $0.44 * * *$ & 0.01 & 0.03 \\
\hline PE_G2 & 0.09 & 0.04 & 1.00 & $0.25 *$ & 0.09 & 0.03 \\
\hline FS_G2 & $0.20 *$ & $0.19 *$ & $0.62 * * *$ & 1.00 & -0.09 & 0.02 \\
\hline PE_G3 & 0.04 & 0.02 & -0.12 & 0.03 & 1.00 & $0.56 * * *$ \\
\hline FS_G3 & 0.10 & -0.05 & -0.17 & -0.07 & $0.58 * * *$ & 1.00 \\
\hline
\end{tabular}

PE: Psychological/Emotional Constraint VOC; FS: Familial/Social Demand VOC PS: Normative/utilitarian VOC; E: Emotional VOC G1: Grandmother; G2: Mother; G3: Adolescent Significance level: ${ }^{* *} p<.001 ;{ }^{* *} p<.01 ;{ }^{*} p<.05$

Source: Own calculations

pattern indicated above. Rural Taiwanese grandmothers as well as Mainland mothers compared to their urban counterparts express greater concern about children's uncertain future than about the cost of having children. Urban Mainland grandmothers are more likely to indicate the familial/social demands of being parents as reasons for not wanting children. Unexpectedly, there is no clear difference across educational groups, or across genders among the adolescents in the two research settings regarding both negative $\mathrm{VOC}$ dimensions.

For the intergenerational transmission of negative VOC dimensions, Table 9 points out that not only fewer significant correlations are found compared to the positive VOC, but there is also no significant effect of value transmission to be found 
among the Taiwanese three-generation samples. The Taiwanese finding implies that when a society has undergone drastic social changes, major constraints related to reproductive values and behaviours tend to be perceived differently across generations. For the Mainland sample, however, both negative VOC dimensions, emotional/psychological as well as familial/social, were transmitted between grandmothers and their adult daughters. Emotional/psychological constraints are also shared by mothers and their teenage children in Mainland China. From unreported analysis of rural and urban differences, a strong link between grandmothers and mothers in both negative VOC dimensions is particularly salient among the rural samples. Urban samples in Mainland China are more likely to reveal a value transmission between grandmothers and their adult daughters in familial/social demands, and between mothers and their teenage children in emotional/psychological constraints of having children. In other words, a negative value transmission concerning not having children among the three generations reveals less significant patterns when compared to the positive VOC transmission, and is mainly restricted to the older generations in Mainland China.

\section{Conclusion and discussion}

With the continuing fertility decline in East Asia, this paper explores values on having children or not in two Chinese societies - Taiwan and Mainland China. It is assumed that by taken into account the cultural homogeneity and political/social heterogeneity between Taiwan and Mainland China, findings will allow us to ascertain whether a similar VOC construct does exist in the Chinese context, and whether the presumed effect of cultural characteristics produce expected outcomes on the VOC. Furthermore, examining the intergenerational transmission among grandmothers, mothers and teenagers of both positive and negative VOC will enable us to delineate the potential influence from the family as well as external societal changes on individual values.

Our findings confirm that it is meaningful to compare the VOC in two culturally homogeneous societies. While separate reports on Taiwan and Mainland China presented three factors solution on VOC, consistent with findings by Nauck and his colleagues (2007; Nauck/Klaus 2007); our direct comparison of Taiwan and Mainland China reveals different results. Two identical factors are generated for both positive and negative VOC in Taiwan and Mainland China. In other words, to echo the earlier speculation by Trommsdorff and Nauck (2005), a more parsimonious two dimensions of VOC is indeed applicable to our research settings. Furthermore, the two dimensions of VOC derived for the Chinese societies clearly reveal the necessity to take into account the dominant familial aspect into the construct in the Chinese context.

For the positive VOC, two extracted factors are traditional and emotional, with the former constituted by traditional utilitarian functions of having children and the latter by the inner psychological reward of having children. While emotional reward receives higher and more consistent ranking across generations for both research 
settings, a gradual decline is observed from grandmothers to mothers and to teenagers for traditional VOC, this trend is more evident in Mainland China than in Taiwan. As to the negative VOC, the psychological/emotional constraint constituted by actual costs of having children is uniformly rated higher than the normative aspect of familial/social demand of raising children across the three generations for both Taiwan and Mainland China. But unlike the positive VOC, the cost of having children reveals a steady increase over generations. In other words, as we move to younger generations, less positive VOC and more negative VOC are reported for both Mainland China and Taiwan. This implies that although the two Chinese societies face different economic experiences, the modernisation effect is quite similar on the general trend of values toward children.

With regard to the intergenerational transmission of $\mathrm{VOC}$, three major findings can be reported: It is more evident for positive VOC, for adjacent generations (e.g., G1-G2, G2-G3) and for respondents in Mainland China. We are able to show that not only fewer significant linkages between generations are found for negative VOC but they are also restricted to the older generations in Mainland China only. In other words, among all dyads examined, values of not wanting children are more likely to be shared among Mainland Chinese grandmothers and mothers. If we add findings on structural mechanisms (i.e., only rural-urban residence, not education nor gender, attains some significant effects), it may be concluded that the intergenerational transmission of positive and negative VOC is most likely to occur among rural Mainland Chinese grandmothers and mothers. In contrast, the intergenerational transmission of VOC does not reveal clear differences in terms of structural background among the Taiwanese counterparts.

The reason that intergenerational transmission appears to be more likely among older rural women in Mainland China may be attributed to the one-child policy in urban areas which prohibits couples from having more children (Lin/Yi 2011). Hence, rural residents, especially the older generational dyad, reveal stronger endorsement on the value of children. Furthermore, more salient generational linkages of traditional VOC implies that the traditional reward of having children is embedded in the normative context that may be transmitted through generations. In accordance with our argument, the cultural meaning of descendants remains tenacious in both Chinese societies.

On the other hand, our findings are unable to support the overall value transmission from grandparents to teenagers. We suspect that the more pronounced linkage of VOC between the grandmother-mother dyad is an outcome of the actual fertility experience. In other words, the actual fertility experience of grandmothers and mothers may lead to the greater likelihood of sharing a similar value of children in the family context. In addition, it should be noted that items falling into positive VOC factors are not entirely the same for Taiwan and Mainland China. A plausible explanation offered in the text suggests the importance of taking into account the cultural characteristics which may connote different meanings as society develops. However, the very fact that two parsimonious factor structures are identified for both research settings supports the strong influence of cultural homogeneity with regard to family values in general. 
In brief, comparing the VOC for Taiwan and Mainland China results in finding more similarities than differences. Not only was an identical factor structure attained but a common trend is also confirmed in that emotional VOC has become the shared value across generations. On the other hand, the salience of the normative as well as utilitarian value of children varies in these two Chinese societies. Benefitting from a longer history of affluence, the economic burden of raising children is no longer important in Taiwan. In contrast, the social expectation of having children maintains its significance among older rural Mainland Chinese. Since urban floating populations and a larger proportion of rural women are included in the Mainland Chinese sample, this may partially explain why traditional and normative concerns of VOC maintain their contemporary tenacity. Lastly, it should be noted that since most VOC studies are restricted to positive VOC only, our study confirms that it is imperative to incorporate both positive and negative VOC in the framework so as to derive a more comprehensive understanding on values of wanting and not wanting children in the contemporary society.

The limitation of this paper addresses a general problem of the instruments used to measure positive and negative VOC in different societies. This study proposes that an ideal construct of VOC in the future should include both positive and negative reasons for wanting and not wanting children. Furthermore, to investigate the fertility intentions in low fertility regions, it is necessary to consider the cultural meaning of having children for the targeted society.

\section{Acknowledgements}

The original version of this paper was presented at a workshop on the "Value of Children and Intergenerational Relations", held at the University of Konstanz, Germany, March 29th-30th, 2012. We thank Prof. Fons J. R. van de Vijver and Prof. Bernhard Nauck for their helpful comments on earlier versions. We also thank two anonymous reviewers for their constructive suggestions.

\section{References}

Arnold, Fred et al. 1975: The value of children: A cross-national study. Volume one. Introduction and comparative analysis. Honolulu, HI: East-West Population Institute.

Blitsten, Dorothy R. 1963: The world of the family: A comparative study of family organizations in their social and cultural settings. New York, NY: Rondom House.

Cai, Yong 2010: China's below-replacement fertility: Government policy or socioeconomic development? In: Population and Development Review 36: 419-440 [doi: 10.1111/j.1728-4457.2010.00341.x].

Chang, Ying-Hwa; Yi, Chin-Chun 2006: Changing attitudes of elderly parents support in Taiwan: Idealized values versus practical concerns. In: Liu, Ts'ui-Jung (Ed.): Essays in honor of Lee Yuan-Tse's 70th birthday II. Taipei, Taiwan: Yun-Chen: 905-939 (in Chinese).

Chen, Yu-Hua; Yi, Chin-Chun 2005: Taiwan's family. In: Adams, Bert; Trost, Jan (Eds.): Handbook of world families. Thousand Oaks, CA: Sage Publications: 177-198. 
Chien, Wen-Yin; Yi, Chin-Chun 2001: The dynamic development of Taiwanese families: Structural fission and expansion. In: Journal of Population Studies 23: 1-47 (in Chinese).

Chien, Wen-Yin 2001: Co-residence with married daughters: Comparative study in Taiwan and Shanghai. In: Journal of Women and Gender Studies 12: 65-94 (in Chinese).

Das Gupta, Monica 2009: Family systems, political systems, and Asia's 'missing girls': the construction of son preference and its unraveling. In: Policy Research Working Paper Series 5148. Washington, DC: The World Bank.

Deutsch, Francine M. 2006: Filial piety, patrilineality, and China's one-child policy. In: Journal of Family Issues 27,3: 366-389 [doi: 10.1177/0192513X05283097].

Freedman, Ronald; Thornton, Arland; Yang, Li-Shou 1994: Determinants of co-residence in extended family. In: Thornton, Arland; Lin, Hui-Sheng (Eds.): Social change and the family in Taiwan. Chicago, IL: University of Chicago Press: 178-201.

Filmer, Deon; Friedman, Jed; Schady, Norbert 2008: Development, modernization, and son preference in fertility decisions. In: Policy Research Working Paper. 4716. Washington, DC: The World Bank.

Hardee-Cleaveland, Karen; Banister, Judith 1988: Fertility policy and implementation in China, 1986-88. In: Population and Development Review 14,2: 245-286 [doi: 10.2307/1973572].

Hoffman, Lois Wladis; Hoffman, Martin L. 1973: The value of children to parents. In: Fawcett, James T. (Ed.): Psychological perspectives on population. New York, NY: Basic Books: 19-76.

Hsu, Francis L. K. 1948: Under the ancestors' shadow: Chinese culture and personality. New York, NY: Columbia University Press.

Hsu, Mei-Ling 1985: Growth and control of population in China: The urban-rural contrast. In: Annals of the Association of American Geographers 75,2: 241-257 [doi: 10.1111/j.1467-8306.1985.tb00084.x].

Jones, Gavin W.; Straughan, Paulin Tay; Chan, Angelique (Eds.) 2009: Ultra-low fertility in Pacific Asia: Trends, causes and policy issues. London: Routledge.

Jones-Farmer, L. Allison; Pitts, Jennifer P.; Rainer, R. Kelly 2008: A note on multigroup comparisons using SAS PROC CALIS. In: Structural Equation Modeling 15: 154-173 [doi: 10.1080/10705510701758414].

Kagitcibasi, Cigdem 2007: Family, self, and human development across cultures: Theory and application (2nd ed.). Mahwah, NJ: Lawrence Erlbaum.

Kankaraš, Milos; Moors, Guy 2009: Measurement equivalence in solidarity attitudes in European: Insights from a multiple-group latent-class factor approach. In: International Sociology 24: 557-579 [doi: 10.1177/0268580909334502].

Koyano, Wataru 1996: Filial piety and intergenerational solidarity in Japan. In: Australian Journal on Ageing 15,2: 51-6 [doi: 10.1111/j.1741-6612.1996.tb00203.x].

Lang, Olga 1968: Chinese family and society. New Haven, CT: Yale University Press.

Lin, Ju-Ping; Yi, Chin-Chun 2011: Filial norms and intergenerational support to aging parents in China and Taiwan. In: International Journal of Social Welfare 20: S109-S120 [doi: 10.1111/j.1468-2397.2011.00824.x].

Logan, John R.; Bian, Fuqin; Bian, Yanjie 1998: Tradition and change in the urban Chinese family: The case of living arrangements. In: Social Forces 76: 851-882 [doi: $10.2307 / 3005696]$ 
Lu, Yu-Hsia 2011: Changes in gender-role attitudes in Taiwan, 1991-2001. In: Taiwanese Journal of Sociology 48: 51-94 (in Chinese).

Löfstedt, Petra; Luo, Shusheng; Johansson, Annika 2004: Abortion patterns and reported sex ratios at birth in rural Yunnan, China. In: Reproductive Health Matters 12,24: 86-95 [doi: 10.1016/S0968-8080(04)24147-7].

McDonald, Peter 2000: Gender equity, social institutions, and the future of fertility. In: Journal of Population Research 17,1: 1-16 [doi: 10.1007/BF03029445].

Mishra, Ramesh C.; Mayer, Boris; Trommsdorff, Gisela; Schwarz, Beate 2005: The value of children in urban and rural India: Cultural background and empirical results. In: Trommsdorff, Gisela; Nauck, Bernhard (Eds.): The value of children in cross-cultural perspective: Case studies from eight societies. Lengerich: Pabst Science: 143-170

Nauck, Bernhard 2007: Value of children and the framing of fertility: Results from a cross-cultural comparative survey in 10 societies. In: European Sociological Review 23: 615-629 [doi: 10.1093/esr/jcm028].

Nauck, Bernhard 2010: Intergenerational relationships and female inheritance expectations: Comparative results from eight societies in Asia, Europe, and North America. In: Journal of Cross-Cultural Psychology 41: 690-705 [doi: 10.1177/0022022110375161].

Nauck, Bernhard; Klaus, Daniela 2007: The varying value of children: Empirical results from eleven societies in Asia, Africa and Europe. In: Current Sociology 55: 487-503 [doi: 10.1177/0011392107077634].

Sung, Kyu-taik 1995: Measures and dimensions of filial piety in Korea. In: Gerontologist 35,2: 240-247 [doi: 10.1093/geront/35.2.240].

Song, Shige; Burgard, Sarah A. 2008: Does son preference influence children's growth in height? A comparative study of Chinese and Filipino children. In: Population Studies 62,3: 305-320 [doi: 10.1080/00324720802313553].

Thornton, Arland; Yang, Li-Shou; Fricke, Thomas E. 1994: Weakening the linkage between the ancestors, the living, and future generations. In: Thornton, Arland; Lin, Hui-Sheng (Eds.): Social change and the family in Taiwan. Chicago, IL: University of Chicago Press: 359-395.

Trommsdorff, Gisela; Zheng, Gang; Tardif, Twila 2002: Value of children and intergenerational relations in cultural context. In: Boski, Pawel; van de Vijver, Fons J. R.; Chodynicka, A. M. (Eds.): New directions in cross-cultural psychology: Selected papers from the fifteenth international conference of the international association for crosscultural psychology. Warszawa, Poland: Polish Psychological Association: 581-601.

Trommsdorff, Gisela; Kornadt, Hans-Joachim 2003: Parent-child relationships in crosscultural perspective. In: Kuczynski, Leon (Ed.): Handbook of dynamics in parent-child relations. London: Sage: 271-306.

Trommsdorff, Gisela; Nauck, Bernhard 2005: Introduction to: The value of children in cross-cultural perspective. Case studies from eight societies. In: Trommsdorff, Gisela; Nauck, Bernhard (Eds.): The value of children in cross-cultural perspective: Case studies from eight societies. Lengerich: Pabst Science: 9-16.

Tseng, Li-Yi; Chang, Chin-Oh; Chen, Shu-Mei 2006: An analysis on the living arrangement choices of the elderly: A discussion on intergenerational relationships. In: Journal of Housing Studies 15,2: 45-64 (in Chinese).

Tu, Su-Hao; Liao, Pei-Shan 2005: Gender differences in gender-role attitudes: A comparative analysis of Taiwan and Coastal China. In: Journal of Comparative Family Studies 36, 4 : 545-566. 
van de Vijver, Fons J. R.; Kwok, Leung 1997: Methods and data analysis for cross-cultural research. Newbury Park, CA: Sage.

Westley, Sidney B.; Choe, Minja Kim 2007: How does son preference affect populations in Asia? In: AsiaPacific Issues 84: 1-12

Whyte, Martin King 1995: From arranged marriages to love matches in urban China. In: Yi, Chin-Chun (Ed.): Marriage formation and dissolution; perspectives from east and west. Taipei, Taiwan: Academia Sinica.

Wu, Ts'ung-Hsien 1977: The value of children: A cross-national study: Taiwan. Honolulu, HI: East-West Center.

Yang, Martin Mou-Chun 1973. Familism and Chinese national character. In: Li, Yih-Yuan; Yang, Kuo-Shu (Eds.): Symposium on the character of the Chinese. Taipei, Taiwan: Institute of Ethnology: 133-179 (in Chinese).

Yang, Ching-Li; Chen, Kuan-Jeng 2002: The reasons and schedules of leaving parental home in Taiwan. In: Journal of Population Studies 25: 120-144 (in Chinese).

Yeh, Kuang-Hui 1997: Parent-child conflicts and their solution types: Discussion from the viewpoint of filial piety. In: Bulletin of the Institute of Ethnology Academia Sinica 82: 65-114 (in Chinese).

Yeh, Kuang-Hui; Yi, Chih-Chun; Tsao, Wei-Chun; Wan, Po-San 2013: Filial piety in contemporary Chinese societies: A comparative study of Taiwan, Hong Kong, and China. In: International Sociology 28,3: 277-296 [doi: 10.1177/0268580913484345].

Yi, Chin-Chun; Pan, En-Ling; Chang, Ying-Hwa; Chan, Chao-Wen 2006: Grandparents, adolescents, and parents: Intergenerational relations of Taiwanese youth. In: Journal of Family Issues 27,8: 1042-1067 [doi: 10.1177/0192513X06288119].

Yi, Chin-Chun; Chang, Ying-Hwa 2008: The continuity and change of patrilineal families: Family sociological research in Taiwan, 1960-2000. In: Shieh, Gwo-Shyong (Ed.): Blooming disciplines: The history of sociological development in Taiwan. Taipei, Taiwan: Socio Publishing Co. Ltd.: 23-73 (in Chinese).

Yi, Chin-Chun; Kung, Hsiang-Ming; Chen, Yu-Hua; Chu, Joujuo 2008: The importance of social context in the formation of the value of children for adolescents: Social class and rural-urban differences in Taiwan. In: Journal of Comparative Family Studies 39: 371-392.

Yu, Wei-Hsin 2009: Gendered trajectories: Women, work, and social change in Japan and Taiwan. Stanford, CA: Stanford University Press.

Zheng, Gang: Liu, Yanfang: Tang, Hong: Shi, Shaohua 2004: Family planning and the value of children in China. In: Setiadi, Bernadette N.; Supratiknya, Augustinus; Lonner, Walter J.; Poortinga, Ype H. (Eds.): Ongoing themes in psychology and culture (Online Ed.). Melbourne, FL: International Association for Cross-Cultural Psychology.

Zheng, Gang; Shi, Shaihua; Tang, Hong 2005: Population development and the value of children in the People's Republic of China. In: Trommsdorff, Gisela; Nauck, Bernhard (Eds.): The value of children in cross-cultural perspective: Case studies from eight societies. Lengerich: Pabst Science: 239-281.

Zheng, Gang; Shi, Shaohua 2006: Intercultural and intracultural differences in the value of children: Comparisons between four countries and the urban, rural, and floating populations in China. In: Zheng, Gang; Leung, Kwok; Adair, John G. (Eds.): Perspectives and progress in contemporary cross-cultural psychology. Beijing, China: China Light Industry Press: 129-148. 
706 • Chin-Chun Yi, Yu-Hua Chen

Dr. Chin-Chun Yi ( $₫)$, Institute of Sociology, Academia Sinica. Taiwan. E-Mail: chinyi@gate.sinica.edu.tw

Dr. Yu-Hua Chen. Department of Bio-Industry Communication and Development, National Taiwan University. Taiwan

E-Mail:yuhuac@ntu.edu.tw 


\section{Comparative Population Studies}

WWW.comparativepopulationstudies.de

ISSN: 1869-8980 (Print) - 1869-8999 (Internet)

Published by / Herausgegeben von

Prof. Dr. Norbert F. Schneider

Federal Institute for Population Research

D-65180 Wiesbaden / Germany

Managing Editor /

Verantwortlicher Redakteur

Frank Swiaczny

Assistant Managing Editor /

Stellvertretende Redakteurin

Katrin Schiefer

Language \& Copy Editor (English) /

Lektorat \& Übersetzungen (englisch)

Amelie Franke

Copy Editor (German) /

Lektorat (deutsch)

Dr. Evelyn Grünheid

\section{Layout / Satz}

Beatriz Feiler-Fuchs

E-mail:cpos@bib.bund.de

\author{
Scientific Advisory Board / \\ Wissenschaftlicher Beirat \\ Paul Gans (Mannheim) \\ Johannes Huinink (Bremen) \\ Michaela Kreyenfeld (Rostock) \\ Marc Luy (Wien) \\ Clara H. Mulder (Groningen) \\ Notburga Ott (Bochum) \\ Peter Preisendörfer (Mainz) \\ Zsolt Spéder (Budapest)
}

\section{Board of Reviewers / Gutachterbeirat} Martin Abraham (Erlangen)

Laura Bernardi (Lausanne)

Hansjörg Bucher (Bonn)

Claudia Diehl (Konstanz)

Andreas Diekmann (Zürich)

Gabriele Doblhammer-Reiter (Rostock)

E.-Jürgen Flöthmann (Bielefeld)

Alexia Fürnkranz-Prskawetz (Wien)

Beat Fux (Salzburg)

Joshua Goldstein (Berkeley)

Karsten Hank (Köln)

Sonja Haug (Regensburg)

Aart C. Liefbroer (Den Haag)

Kurt Lüscher (Konstanz)

Dimiter Philipov (Wien)

Tomáš Sobotka (Wien)

Heike Trappe (Rostock) 